\title{
Physicochemical Profile of Essential Oils Obtained from Chia (Salvia hispanica L.) Seeds Grown in Different Agro-Ecological Zones of Kenya
}

\author{
Clement Komu, Monica Mburu, Daniel Njoroge, and Richard Koskei
}

\section{ABSTRACT}

The chia seed samples were purchased from farmers in five locations in three agro-ecological zones in Kenya. The oil was obtained by cold pressing and physicochemical properties were determined; the fatty acid profile was determined by Gas chromatography. The mean oil yield from pressing was $16 \%$, the refractive index of chia seed oil at $25^{\circ} \mathrm{C}$ ranged from 1.4811 to 1.4832 , specific gravity ranged from 0.9616 to 0.9629 , acidity index and free fatty acids content ranged from $0.0345-0.0808 \mathrm{mg} \mathrm{KOH} / \mathrm{g}$ oil, and $0.1736-0.4061 \%$, respectively. The matter in volatiles ranged from $0.047-0.086 \%$. The saponification value ranged from 162.1969-183.3791 milligrams $(\mathrm{mg})$ of potassium hydroxide (KOH) per gram (g) of chia seed oil. The differences in refractive index, acidity index, free fatty acids, specific gravity, and saponification value, were statistically significant at $(P<0.05)$. The $\alpha$-linolenic (C18:3) and linoleic acids (C18:2) were the dominant fatty acids in chia seed oil and they varied with regions. The levels $\alpha$-linolenic (C18:3) and linoleic acids (C18:2) ranged from 53.32-64.04\% and 19.37-22.87\%, respectively. The levels of oleic, linoleic, and linolenic fatty acids in chia seed oils from different regions were statistically significant at $(P<0.05)$. The study recommended the cultivation of chia seed in agro-ecological zones II and III where higher yields and higher content of linoleic and linolenic fatty acids were reported, consumption of chia seed oil as edible oil, and substitution of marine oils with chia oil as potential sources of polyunsaturated fatty acids.

Keywords: alpha-linolenic acids, Chia seeds, Omega-3 fatty acid, polyunsaturated fatty acids, Salvia hispanica L.

\author{
Published Online: August 15, 2021 \\ ISSN: $2684-4478$ \\ DOI : $10.24018 /$ ejchem.2021.2.3.56 \\ Clement Komu* \\ Institute of Food Bioresources \\ Technology, Dedan Kimathi University \\ of Technology, Private Bag, Dedan \\ Kimathi, Nyeri, Kenya. \\ (e-mail: clementmumo@ ${ }^{\circledR}$ gmail.com) \\ Monica Mburu \\ Institute of Food Bioresources \\ Technology, Dedan Kimathi University \\ of Technology, Private Bag, Dedan \\ Kimathi, Nyeri, Kenya. \\ Daniel Njoroge \\ Institute of Food Bioresources \\ Technology, Dedan Kimathi University \\ of Technology, Private Bag, Dedan \\ Kimathi, Nyeri, Kenya. \\ Richard Koskei \\ Institute of Food Bioresources \\ Technology, Dedan Kimathi University \\ of Technology, Private Bag, Dedan \\ Kimathi, Nyeri, Kenya. \\ *Corresponding Author
}

\section{INTRODUCTION}

The consumption of saturated and unsaturated fatty acids over the last 100 years is not consistent with the evolutionary aspects of the human diet, this has predisposed humans to chronic diseases such as coronary heart disease, hypertension, diabetes, arthritis and possibly cancer [1]. The health concerns associated with the consumption of hydrogenated and saturated fats have made the replacement of saturated and trans-fats with healthier unsaturated fats in human diets to become one of the significant focus areas for food and nutrition research [2]. These concerted research efforts have led to the rediscovery of the chia plant, a food crop of the ancient American civilizations. Chia seed oil is an exciting source of polyunsaturated fatty acids (PUFAS) as it contains the highest proportion of $\alpha$-linolenic acid (approximately $60 \%$ ) of any known vegetable sources [3]. These fatty acids belong to the $\omega-6$ family which is essential for the growth and development of the human body and also plays a vital role in the prevention and treatment of coronary heart disease, hypertension, diabetes, arthritis, other inflammatory and autoimmune disorders and cancer [4].
Due to the health concerns associated with saturated and trans fats, there has been the development of underexploited, but promising plant species as sources of speciality oils in recent years [5]. Most of these speciality oils contain significant quantities of nutritionally desirable fatty acids such as $\omega-3$ and $\omega-6$ fatty acids, which are essential for the prevention of cardiovascular diseases. Some of the sources of these speciality oils include flax and chia seeds; they contain bioactive compounds and high proportions of polyunsaturated fatty acids. Salvia hispanica $L$., also known as chia, was widely used by Aztec tribes for food, medicine, and paints [6].

Chia is valued mostly due to the seed composition, [5] reported that chia seed contains approximately $40 \%$ of the total weight as oil, with almost $60 \%$ of the lipids comprising omega-3 fatty acids, 30\% dietary fiber, and 19\% high biological value protein. The chemical compositions and yield of chia oils may be affected by many factors such as ecological conditions, extraction methods, the genotype of chia seeds, crops growing length and variations in climatic conditions [5], [6]. 
The chemical composition and nutritional value of the chia seed can vary depending on the climatic conditions and location of growing [7]. The seed oil content tends to increase as the altitude of cultivation increases and an increase in temperature during grain development produces a reduction in the production of polyunsaturated fatty acids [8].

According to [9], the geographical area and climate can influence the concentration of nutrients in chia seeds. The seed oil yield, $\alpha$-linolenic acid and linoleic acid content of chia seeds grown in different locations including, Brazil, Argentina, and Mexico have been shown to vary [9], [11]. The observed differences suggested a strong influence of geographical location, climatic conditions and agronomic practices on chia oil yield and oil biochemical composition [12]. However, although the production of chia in Kenya and East African countries has gradually increased, there is limited data on the physicochemical characteristics of oil from the chia seeds grown in Kenya. Therefore, this study intends to characterize the seed oil from chia grown in different agro-ecological zones in Kenya.

The study aimed to determine oil yield, physicochemical properties and fatty acid profile from chia seed oil grown in different agro-ecological zones in Kenya. Further, the study sought to determine if there were differences in the oil yield, physicochemical properties and fatty acid profile from chia grown in different agro-ecological zones.

\section{METHOD}

\section{A. Materials}

Chia (S. hispanica) seeds were sourced from five farmers located in three agro-ecological zones. The analytical samples were drawn randomly from the purchased sample by use of a sample splitter; the chia oil was extracted by cold pressing. The analysis of the extracted oil was conducted in duplicates to minimize variations due to the analytical methods. The oil obtained was analyzed in triplicates to determine its physicochemical properties.

\section{TABLE I: ECOLOGICAL ZONES OF CHIA CULTIVATION}

\begin{tabular}{cccc}
\hline Location & Altitude & Mean Rainfall & $\begin{array}{c}\text { Ecological } \\
\text { Zone }\end{array}$ \\
\hline Mbeere & 1143 meters & 706 milliliters & Zone IV \\
Kivaa & 1020 meters & 700 milliliters & Zone IV \\
Nyahururu & 2360 meters & 978 milliliters & Zone II \\
Nyeri & 1800 meters & 1000 milliliters & Zone III \\
Mwea & 1150 meters & 850 milliliters & Zone IV \\
\hline
\end{tabular}

\section{B. Chia Seed Oil Extraction}

The chia seed oil was extracted by cold pressing. The precleaned chia seeds from each location were weighed and put into the screw press hopper and extraction was carried out in a single step for $10-15$ minutes at a temperature of $40-50{ }^{\circ} \mathrm{C}$.

\section{Research Design}

Completely Randomised Design (CRD) was used in this study. Five kilograms of chia seed samples each were purchased from farmers five locations in three agroecological zones from July to September 2019. The analysis of the extracted oil was conducted in triplicates to minimize variations due to the analytical methods.

\section{Physicochemical Characterization of Chia Oil}

The weight per unit volume and specific gravity, index of refraction, saponification value, free fatty acids, iodine value, peroxide value, matter in volatiles were determined using [13] and fatty acid profile was determined using gas chromatography.

\section{Index of Refraction Determination}

The refractive index of the chia seed oil was determined according to AOAC official method 921.08 [13]. Three drops of oil were placed on the refractometer prism; the prism was then closed by tightening screw heads. Water was circulated through the instrument for a few minutes before the readings were taken; this was to allow the equilibration of the temperature of the test sample and instrument. The prism was cleaned between readings by wiping off oil with a cotton pad moistened with ethyl alcohol and left to dry.

\section{Determination of Specific Gravity}

The specific gravity of the chia seed oil was determined using AOAC method 985.19 [13] in this method specific gravity of a given volume of liquid fat at desired temperature was determined with a pycnometer previously calibrated at the same temperature.

The cleaned and dried pycnometer was weighed and filled with water and the pycnometer temperature was adjusted to $20{ }^{\circ} \mathrm{C}$ in a water bath held at $20{ }^{\circ} \mathrm{C}$. The water level in the pycnometer was adjusted to the level of the fixed mark. The pycnometer was removed from the water bath, wiped dry, allowed to stand for a short time and weighed. The empty and dried pycnometer was was filled with the sample of the oil previously brought near temperature $20^{\circ} \mathrm{C}$. The pycnometer oil level was adjusted to the mark, kept in a water bath until it attained $20^{\circ} \mathrm{C}$. The oil temperature was then maintained at $20{ }^{\circ} \mathrm{C}$ until no further alteration in volume occurred. The pycnometer was then removed from the water bath wiped dry and adjusted to the fixed mark allowed to stand for a short time and weighed. This procedure was repeated for each sample and results recorded.

\section{Determination of Saponification Value}

The saponification number is the number of milligrams of potassium hydroxide required to neutralize the fatty acids from the complete hydrolysis of one gram of fat. Saponification number is the measure of chain length of fatty acids. The saponification value was determined according to AOAC method 920.160 [13]. This method involved boiling a sample under reflux with ethanolic potassium hydroxide solution, followed by titration of the excess potassium hydroxide with the standard volumetric hydrochloric acid solution.

Two grams of chia seed oil was mixed with 25 milliliters of 4 per cent alcoholic potassium hydroxide by draining it from the burette for a definite time. The contents were refluxed for one hour and then cooled. The cooled solution was titrated against $0.5 \mathrm{~N}$ hydrochloric acid using a phenolphthalein indicator. Simultaneously a blank was run adapting a similar procedure. The saponification number was calculated using the formula below.

Saponification number $=\frac{28.05(\mathrm{~B}-\mathrm{S})}{\text { Sample } \mathrm{wt}(\mathrm{g})}$ 
$\mathrm{B}=\mathrm{ml} 0.5 \mathrm{~N}$ HCL required by blank;

$\mathrm{S}=\mathrm{ml} 0.5 \mathrm{~N}$ HCL required by blank.

\section{Free Fatty Acids}

The free fatty acid content (as oleic) of the crude oil was determined using the titration method described in AOAC method 940.28 [13]. One gram of oil was added to seven milliliters of ethanol previously neutralized by phenolphthalein. The titration was done by adding $0.1 \mathrm{M}$ sodium hydroxide $(\mathrm{NaOH})$ to the mixture.

The free fatty acid (FFA) level (as oleic) was calculated using the following equation.

$\%$ FFA $($ oleic $)=\frac{(\text { volume }) \text { alkali } \times \text { Normality of alkali } \times 28.2}{\text { Sample } w t(g) \times 1000}$

The acid value of the chia seed oil was also calculated from the titration results using the following equation.

$$
\text { Acid value }=\frac{56.1 \times \text { volume of alkali } \times \text { Normality }}{\text { Sample } w t(g)}
$$

\section{Matter in Volatiles}

The matter in volatiles was determined using AOAC method 926.12 [13]. 3.5 grams of the chia seed oil were put in aluminium moisture dishes $(5 \mathrm{~cm}$ in diameter and $2 \mathrm{~cm}$ deep) with a tight fit slip over cover. The oil in the moisture dishes was dried in a vacuum oven maintained at $120-125^{\circ} \mathrm{C}$ for 30 minutes until a constant weight was attained. The percentage loss in weight was reported as percentage moisture in volatiles.

The calculation was done as per the equation below:

$$
\text { Moisture and matter in volatiles }=\frac{\mathrm{w} 1 \times 100}{\text { Sample } \operatorname{wt}(\mathrm{g})}
$$

where W1= Loss in Weight in gram of the sample on drying.

\section{Fatty Acid Profile}

Fatty acid profile was determined by gas chromatography analysis, conventional saponification procedure described by Ichiahara et al. [14]. The fatty acids were converted into their respective methyl esters before analysis. Fifty milligrams of the oil were mixed with $2 \mathrm{ml}$ of $0.5 \mathrm{M}$ methanolic potassium hydroxide $(\mathrm{KOH})$ in screw-capped glass tubes. These tubes were stirred for 5 minutes and then held at $70^{\circ} \mathrm{C}$ for one hour to facilitate the release of fatty acids from the triglycerides. After acidification with $0.5 \mathrm{ml}$ of hydrochloric acid (HCL), the released fatty acids were then extracted twice using $5 \mathrm{ml}$ of hexane, then $5 \mathrm{ml}$ of boron trifluoride-methanol mixture $(14 \% \mathrm{~W} / \mathrm{V})$ was added into the fatty acid mixture and vortexed for 5 minutes at ambient temperature. The fatty acid methyl esters (FAMEs) were then extracted from the methanolic phase by the addition of $4 \mathrm{ml}$ of hexane. Subsequently, $1 \mu$ of a hexane solution containing the FAMES were injected into the column of gas chromatography (Hewlett Packard 6890) equipped with capillary column DB-23 Agilent (50\% cyanopropylmethylpolysiloxane, $60 \mathrm{~m}-0.25 \mathrm{~mm}$, internal diameter 0.25 $\mu \mathrm{m})$, equipped with flame ionization detector (FID). Separation was carried out at $175-220{ }^{\circ} \mathrm{C}$ at $\left(3^{\circ} \mathrm{C}\right.$ per minute $)$ with helium as the carrier (25.1 psi) and a flame ionization detector at $260{ }^{\circ} \mathrm{C}$ [15]. The fatty acid methyl esters (FAMEs) were then identified through comparison of retention times of FAMES standard mixture analyzed under the same conditions, the FAMEs in the extracted chia seed oil were quantified using peak area normalization. The results were expressed as the relative percentage of each fatty acid present in the sample.

\section{Data Analysis}

Each separate set of chia seed oil was analysed in triplicates. Data was analyzed using SPSS version 25. The significance of the differences in refractive index, specific gravity, saponification value, free fatty acids, acid value, matter in volatiles, and fatty acid profile among the chia seed oil from different agro-ecological zones was determined. To test the significance of the differences in chia seed oil extracted from different locations, for each variable analyzed. Data was processed by one-way analysis of variance ANOVA. The differences were considered significant at $\mathrm{P}<0.05$.

\section{RESULTS AND DISCUSSION}

\section{A. Oil Yield}

Table II shows the oil yield from chia seeds grown in different agro-ecological zones in Kenya. The mean oil yield from the chia seeds from the five ecological zones was $16.23 \%$. The highest oil yield was reported in chia seeds from Mwea at $17.79 \%$ located in ecological zone IV while the lowest yield was reported in chia seeds from Kivaa at $12.85 \%$ located in ecological zone IV. The differences in oil yield of chia seed oil from chia grown in different ecological zones were statistically significant at $(\mathrm{P}<0.05)$. This difference could be attributed to the differences in rainfall, temperatures, soil, attitude, and agronomic practices in each of the locations [16].

The results were lower than levels reported in other studies such as [16] and [17]. [18] and [19] who reported oil yield in the range of $20.3 \%-35.3 \%$. The lower oil yield could be attributed to lower seed oil content due to genetic and environmental factors [20]. The chia seed oil contents were shown to be affected by the environment of cultivation. It was observed that the seeds oil content tended to increase as the altitude of the ecosystem where the seeds were grown increased; however, the differences in oil content were not always significant $(\mathrm{P}<0.05)$ [2]. [2] reported that the extraction parameters, such as the efficiency of the method applied, could also influence the oil yield from the extraction process.

TABLE II: OIL YIELD OF KENYAN CHIA SEEDS FROM DIFFERENT AGRO-

\begin{tabular}{ccc}
\multicolumn{3}{c}{ ECOLOGICAL ZONES } \\
\hline Ecological Zone & Location & Oil Yield (\%) \\
\hline III & Nyeri & $16.23 \pm 0.14 \mathrm{ab}$ \\
IV & Mwea & $17.80 \pm 0.10 \mathrm{~b}$ \\
II & Nyahururu & $15.58 \pm 0.48 \mathrm{ab}$ \\
IV & Mbeere & $17.75 \pm 0.10 \mathrm{~b}$ \\
IV & Kivaa & $12.85 \pm 0.06 \mathrm{a}$ \\
\hline
\end{tabular}

${ }^{1}$ values are means $( \pm \mathrm{SD})$ of duplicate determinations.

${ }^{2}$ means designated by different letters in a row are significantly different at $(\mathrm{P}<0.05)$. 


\section{B. Physicochemical Properties}

The data for physicochemical properties of chia seed oil such as free fatty acids, acid value, specific gravity, saponification value, refractive index and matter in volatiles was presented in Table III. Refractive index and specific gravity are essential parameters in determining the authenticity of oils to detect adulteration (21). In this study, the refractive index of chia seed oil at $25{ }^{\circ} \mathrm{C}$ was found to range from 1.4811 to 1.4832 . The highest refractive index was reported in chia seed oil from seeds grown in Nyeri (1.4832), and this was closely followed by oil from Nyahururu at 1.4832 and 1.4830 , respectively. These two locations were in agro-ecological zones III and II, respectively. These zones were found in high altitude areas which experience lower mean temperatures and higher rainfall compared to other locations. Lower refractive index levels were reported in locations that were in agro-ecological zone IV, which had lower altitudes and relatively higher temperatures. The chia seed in agro-ecological IV, which include Kivaa, Mbeere and Mwea reported a refractive index of 1.4816, 1.4816 and 1.4812, respectively. According to (6), cold temperatures were shown to favour higher levels of unsaturation in other oil crops. The Refractive index was significant on oil from different locations $\mathrm{P}<0.05$. This was attributed to differences in the level of unsaturation.

The refractive index levels reported in this study were lower than reported by [18], in which, chia oil was reported to have a refractive index value of 1.4761 at $25^{\circ} \mathrm{C}$. However, the findings of this study are similar to those of [5] and [21] who reported refractive index at $25^{\circ} \mathrm{C}$ of 1.48 . According to [18], the refractive index is directly related to the level of unsaturation of the oil and a higher refractive index is associated with a higher level of unsaturation. The refractive index was higher than that reported for palm oil, palm stearin, pistachio oil, rapeseed oil, rice bran oil, sunflower seed oil and walnut oil which ranged from 1.4581 to 1.475 as influenced by the higher content of unsaturated fatty acids [22]. The differences in the refractive index of chia seed oil extracted from chia seeds grown in different ecological zones were statistically significant at $(\mathrm{P}<0.05)$. This was attributed to differences in ecological conditions at these locations.

The specific gravity in this study was found to range from 0.9616 to 0.9629 . The highest specific gravity was found in chia seed oil from Zone III, Nyeri, at 0.9629. There were significant differences in the specific gravity of chia seed oil obtained from different locations. The differences in the specific gravity were due to differences in agro-ecological conditions which include temperature and elevation. The findings were inconsistent with the finding of [21] who reported specific gravity of 0.93 in Australian chia seed oil and $[18$ who reported a specific gravity of 0.92 in Mexican chia seed oil. The specific gravity of Kenyan chia seed oil was lower than that of palm oil, palm stearin, pistachio oil, rapeseed oil, rice bran oil, sunflower seed oil and walnut oil which ranged from 0.899 to 0.923 [22].

Chemical characterization showed that chia seed oil registered an acidity index that ranged from 0.0345- 0.0808 $\mathrm{mg} \mathrm{KOH} / \mathrm{g}$ oil, and free fatty acids ranged from $0.1736-$ $0.4061 \%$ (as oleic acid). The lowest acid value of $0.1736 \mathrm{mg}$ $\mathrm{KOH} / \mathrm{g}$ oil and a free fatty acid value of $0.0345 \%$ (as oleic) was found in chia seed oil from agro-ecological zone III. This was followed by chia seed oil from agro-ecological zone II, where free fatty acid of $0.211 \mathrm{mg} \mathrm{KOH} /$ gram oil was reported. The highest levels of acid value and free fatty acids were reported in chia seed oil agro-ecological zone IV. The acid value and free fatty acids in these locations ranged from 0.2125-0.4061 mg KOH/gram of oil and 0.0423-0.0808\% (as oleic acid), respectively. The acid value and free fatty acids contents of chia seed oil from Ecological zone IV (Kivaa location) were significantly different from chia seed oil from other locations at $\mathrm{p}<0.05$. This was attributed to a higher concentration of saturated fatty acids which led to a more rapid oxidation rate compared to chia seed oil from other locations. The reported levels of acid value were below limits stated in the Codex standard for named vegetable oils which is a maximum of $4 \mathrm{mg} \mathrm{KOH} / \mathrm{g}$ oil (22). This was because the cold-pressed chia seed oil was freshly analyzed after extraction and had not undergone oxidation. His could also be attributed to the higher content of antioxidants in the coldpressed oil which served to stabilize the oil and inhibit oxidation.

The findings were lower than reported for chia grown in other regions, acid values of $0.7-0.91 \%$ were reported for Argentian chia seed oil and $2.053 \%$ was reported for Mexican chia seed [5], [17]. The results of the study were also comparable to oil from similar oil crops such as Moringa which reported an acid value of $0.29-0.37 \%$ [23].

In the study, the matter in volatiles was observed to range from $0.0469-0.0863 \%$. The highest matter in volatiles was in chia seed oil from agro-ecological zone IV, which included Mwea Mbeere and Kivaa locations where they showed matter in volatiles of $0.0863 \%, 0.0622 \%$ and $0.469 \%$, respectively. Lower matter in volatiles was observed in agro-ecological zone II and III, which were Nyeri and Nyahururu locations and showed matter in volatiles level of $0.0532 \%$ and $0.0469 \%$, respectively. The differences in the matter in volatiles of chia seed oil extracted from chia seeds grown in different ecological zones were statistically significant at $(\mathrm{P}<0.05)$. The differences in the matter in volatiles could be attributed to the ecological conditions where the chia seeds were cultivated, post-harvest handling and oil extraction parameters [2]. The findings were below the requirements of [22], where the maximum acceptable matter in volatile is $0.2 \%$. Matter in volatiles has been used for quality control of edible oils such as olive oil for detection of adulterants, rancidity and to determine the oil origin [24].

The saponification value shown in the results ranged from 162.1969-183.3791 milligrams (mg) of potassium hydroxide $(\mathrm{KOH})$ per gram $(\mathrm{g})$ of chia seed oil. The saponification value decreased from agro-ecological zone II to IV. The highest saponification value was reported in chia oil obtained from chia grown in ecological zone II, and the saponification value was $183.3791 \mathrm{mg}(\mathrm{KOH})$ per gram of oil. This was followed by chia oil from Chia seeds grown in agro-ecological zone III, and the saponification value was at $180.1250 \mathrm{mg}(\mathrm{KOH})$ per gram of oil. The lowest saponification value was observed in chia oil from seeds grown in agro-ecological zone IV. The saponification value was $162.1970,163.7544$ and 170.4418 mg $(\mathrm{KOH})$ per gram of oil for Kivaa, Mbeere and Mwea, respectively.

The saponification values reported in the study were in the same range as reported in Australian chia seed which was 197 
$\mathrm{mg} \mathrm{KOH} / \mathrm{g}$ of oil [21] and was lower than those reported in Mexican chia seed oil which was $222 \mathrm{mg} \mathrm{KOH} / \mathrm{g}$ of oil. The reported saponification values were in the same range as reported for sunflower, safflower, and virgin olive oil [22]. These findings suggested that the molecular weights of the fatty acids in the chia seed oil were in the same range as was in sunflower, safflower, and virgin olive oil. The differences in saponification values of chia seed oil extracted from chia seeds grown in different ecological zones were statistically significant at $(\mathrm{P}<0.05)$.

TABLE III: PHYSICOCHEMICAL CHARACTERISTICS OF CHIA SEED OIL

\begin{tabular}{|c|c|c|c|c|c|c|}
\hline Ecological Zone & Free fatty acids & Acid value & $\begin{array}{l}\text { Specific } \\
\text { Gravity }\end{array}$ & $\begin{array}{c}\text { Saponification } \\
\text { Value }\end{array}$ & Refractive Index & $\begin{array}{c}\text { Matter in } \\
\text { volatiles }\end{array}$ \\
\hline IV-Mwea & $0.24 \pm 0.00^{\mathrm{a}}$ & $0.05 \pm 0.00^{\mathrm{a}}$ & $0.96 \pm 0.00^{\mathrm{a}}$ & $170.44 \pm 3.81^{\mathrm{a}}$ & $1.4812 \pm 0.0001^{\mathrm{a}}$ & $0.07 \pm 0.00^{\mathrm{a}}$ \\
\hline IV -Mbeere & $0.21 \pm 0.02^{\mathrm{a}}$ & $0.04 \pm 0.00^{\mathrm{a}}$ & $0.96 \pm 0.00^{\mathrm{a}}$ & $163.75 \pm 3.08^{\mathrm{a}}$ & $1.4816 \pm 0.0001^{\mathrm{b}}$ & $0.06 \pm 0.02^{\mathrm{a}}$ \\
\hline IV -Kivaa & $0.41 \pm 0.01^{\mathrm{b}}$ & $0.08 \pm 0.00^{\mathrm{b}}$ & $0.96 \pm 0.00^{\mathrm{a}}$ & $162.20 \pm 2.88^{\mathrm{a}}$ & $1.4812 \pm 0.0001^{\mathrm{a}}$ & $0.08 \pm 0.01^{\mathrm{a}}$ \\
\hline II- Nyahururu & $0.21 \pm 0.01^{\mathrm{a}}$ & $0.04 \pm 0.00^{\mathrm{a}}$ & $0.96 \pm 0.00^{\mathrm{b}}$ & $182.38 \pm 0.08^{\mathrm{b}}$ & $1.4830 \pm 0.0001^{\mathrm{c}}$ & $0.05 \pm 0.01^{\mathrm{a}}$ \\
\hline III -Nyeri & $0.17 \pm 0.01^{\mathrm{a}}$ & $0.03 \pm 0.00^{\mathrm{a}}$ & $0.96 \pm 0.00^{\mathrm{ab}}$ & $180.13 \pm 1.38^{\mathrm{ab}}$ & $1.4832 \pm 0.0001^{\mathrm{d}}$ & $0.05 \pm 0.01^{\mathrm{a}}$ \\
\hline
\end{tabular}

1 values are means $( \pm$ SD) of duplicate determinations.

${ }^{2}$ means designated by different letters in a row are significantly different at $(\mathrm{P}<0.05)$.

\section{Fatty Acids Profile}

Gas chromatography analysis of oil from all the locations indicated the presence of linoleic acid, oleic, $\alpha$-linolenic palmitic and stearic fatty acids. Traces of twelve more fatty acids were detected, which included butyric, caproic, myristic, pentacyclic, palmitoleic, margaric, arachidic, eicosenoic, eicosadienoic, eicosatrienoic, behenic and lignoceric acids.

There was a significant difference $(\mathrm{P}<0.05)$ in fatty acid composition in the oil from chia grown in the five locations in linoleic, linoleic, and linolenic fatty acids. This was due to differences in agro-ecological conditions which included temperature, altitude soil type and the amount of rainfall in the area of cultivation.

In agro-ecological zone IV, the highest levels of unsaturated fatty acids oleic and linoleic fatty acids were reported the levels of oleic and linoleic fatty acids ranged from $9.74-9.83 \%$ and $22.71-22.90 \%$, respectively. The agroecological zones II and III reported the highest levels of linolenic fatty acids compared to agro-ecological zone IV and the linolenic fatty level ranged from 61.06-64.04\% The results were similar to findings by [5] and [25]. This suggested that the fatty acid composition of chia seed oil was dependent on environmental factors such as climatic conditions, nutrient availability and soil type and condition; also, it can be affected by seed maturity [2].

The findings of this study were consistent with the findings by [12], who reported that the level of unsaturation of fatty acids tended to increase as the altitude of the cultivation of chia increased. These findings were valid for chia grown in agro-ecological zones III and IV; however, the study reported mixed findings for chia seed oil from ecological zone II which was found to have lower levels of oleic, linoleic, and linolenic acids than that from the agro-ecological zone III which was located in a lower altitude.

[2] reported an inverse relationship between altitude and the content of saturated fatty acids, at low elevation, which is associated with higher temperatures, where increased fatty acids saturation was observed.

TABLE IV: FATTY ACID COMPOSITION OF KENYAN CHIA SEED SAMPLES EXPRESSED AS \% FATTY ACID IN RELATION TO TOTAL FATTY ACID

\begin{tabular}{|c|c|c|c|c|c|c|c|c|c|c|c|c|c|c|c|c|c|}
\hline $\begin{array}{l}\text { Ecological } \\
\text { zone }\end{array}$ & $\mathrm{C} 4: 0$ & C8:0 & $\begin{array}{c}\text { C14: } \\
0 \\
\end{array}$ & $\begin{array}{c}\text { C15: } \\
0 \\
\end{array}$ & $\begin{array}{c}\text { C16: } \\
0 \\
\end{array}$ & $\begin{array}{c}\text { C16: } \\
1\end{array}$ & $\begin{array}{c}\text { C17: } \\
0 \\
\end{array}$ & $\begin{array}{c}\text { C18: } \\
0 \\
\end{array}$ & $\begin{array}{c}\text { C18: } \\
1 \\
\end{array}$ & C18:2 & C18:3 & $\begin{array}{c}\mathrm{C} 20: \\
0\end{array}$ & $\begin{array}{c}\mathrm{C} 20: \\
1\end{array}$ & $\begin{array}{c}\text { C20: } \\
2\end{array}$ & $\begin{array}{c}\mathrm{C} 20: \\
3\end{array}$ & $\begin{array}{c}\text { C22: } \\
0\end{array}$ & $\begin{array}{c}\text { C24: } \\
0\end{array}$ \\
\hline III-Nyeri & 0.04 & 0.01 & 0.04 & 0.02 & 7.31 & 0.06 & 0.04 & 2.84 & $5.07^{\mathrm{a}}$ & $19.40^{\mathrm{a}}$ & $64.04^{\mathrm{a}}$ & 0.25 & 0.28 & 0.02 & 0.02 & 0.06 & 0.09 \\
\hline IV -Mwea & 0.02 & 0.02 & 0.06 & 0.03 & 8.06 & 0.05 & 0.05 & 4.31 & $9.74^{\mathrm{b}}$ & $22.71^{\mathrm{b}}$ & $53.61^{\mathrm{b}}$ & 0.33 & 0.23 & 0.03 & 0.02 & 0.12 & 0.17 \\
\hline $\begin{array}{c}\text { II- } \\
\text { Nyahururu }\end{array}$ & 0.02 & 0.02 & 0.05 & 0.03 & 7.30 & 0.05 & 0.04 & 3.65 & $7.26^{\mathrm{c}}$ & $19.37^{\mathrm{c}}$ & $61.06^{\mathrm{c}}$ & 0.28 & 0.25 & 0.04 & 0.03 & 0.09 & 0.12 \\
\hline IV-Mbeere & 0.02 & 0.01 & 0.06 & 0.03 & 8.01 & 0.06 & 0.05 & 4.31 & $9.78^{\mathrm{d}}$ & $22.87^{\mathrm{d}}$ & $53.98^{\mathrm{d}}$ & 0.33 & 0.22 & 0.03 & 0.02 & 0.07 & 0.14 \\
\hline IV-Kivaa & 0.03 & 0.02 & 0.06 & 0.03 & 8.13 & 0.06 & 0.05 & 4.25 & $9.83^{\mathrm{e}}$ & $22.90^{\mathrm{e}}$ & $53.32^{\mathrm{e}}$ & 0.33 & 0.25 & 0.03 & 0.02 & 0.07 & 0.02 \\
\hline
\end{tabular}

${ }^{2}$ means designated by different letters in a row are significantly different at $(\mathrm{P}<0.05)$.

\section{CONCLUSION}

The average oil yield from chia seeds from the three ecological zones was $16 \%$ oil. The differences in free fatty acid, acid value, refractive index, specific, saponification value, and oil yield were significant $(\mathrm{P}<0.05)$. The different levels of unsaturated fatty acids were reported in different agro-ecological zones. In agro-ecological zone IV, the levels of oleic, linoleic, and linolenic fatty acids ranged from 9.74$9.83 \%, 22.71-22.90 \%$ and $53.61-53.98 \%$, respectively. The levels of saturated fatty acids palmitic and stearic decreased as the altitude of cultivation of the chia seeds increased. The levels of monounsaturated fatty acid (oleic fatty acid), and other polyunsaturated fatty acids linoleic and linolenic were inversely related, higher levels of oleic fatty acid were reported in oil from chia seeds grown in ecological zone IV compared to chia seed from seeds grown in ecological zone II and III. The levels of polyunsaturated fatty acids linoleic and linolenic increased as the altitude of cultivation increased.

\section{ACKNOWLEDGEMENTS}

This study was carried out at the Technical Facility of the Institute of Food Bioresources Technology, Dedan Kimathi University of Technology, funded by the National Research Fund, Kenya. I am grateful for the assistance of Dr Monica Mburu, Dr Daniel Njoroge and Dr Richard Koskei in critically reviewing the document. 


\section{REFERENCES}

[1] Simopoulos, A. P. (1998). Overview of evolutionary aspects of w3 fatty acids in the diet. World review of nutrition and dietetics, 83, 1-11.

[2] Ayerza, R. (2010). Effects of seed colour and growing locations on fatty acid content and composition of two chia (Salvia hispanica L.) genotypes. Journal of the American Oil Chemists' Society, 87(10), 1161-1165.

[3] Ayerza, R. (1995). Oil content and fatty acid composition of chia (Salvia hispanica L.) from five northwestern locations in Argentina Journal of the American Oil Chemists' Society, 72, 1079-1081.

[4] Simopoulos, A. P. (2008). The importance of the omega-6/omega-3 fatty acid ratio in cardiovascular disease and other chronic diseases. In Experimental Biology and Medicine (Vol. 233, Issue 6, pp. 674-688) https://doi.org/10.3181/0711-MR-311.

[5] 5.Ixtaina, V.Y., Martínez, M.L., Sportono, V., Mateo, C.M., Maestri, D.M., Diehl, B.W.K., Nolasco, S.M. and Tomas, M.C. (2011) characterization of chia seed oils obtained by pressing and solvent extraction. Journal of Food Composition and Analysis, 24, 166-174.

[6] Ayerza, R. \& Coates, W. (1996). Production potential of chia in northwestern Argentina Production potential of chia in northwestern Argentina. In Industrial Crops and Products (Vol. 5). https://www.researchgate.net/publication/314924868.

[7] 7.Da Silva, B. P., Anunciação, P. C., Matyelka, J. C. da S., Della Lucia, C. M., Martino, H. S. D., and Pinheiro-Sant'Ana, H. M. (2017) Chemical composition of Brazilian chia seeds grown in different places. Food Chemistry, 221, 1709-1716. https://doi.org/10.1016/j.foodchem.2016.10.115.

[8] Baginsky, C., Arenas, J., Escobar, H., Garrido, M., Valero, N., Tello, D., \& Silva, H. (2016). Growth and yield of chia (Salvia hispanica L.) in the Mediterranean and desert climates of Chile. Chilean journal of agricultural research, 76(3), 255-264.

[9] Ayerza, R., \& Coates, W. (2009). Influence of environment on growing period and yield, protein, oil and $\alpha$-linolenic content of three chia (Salvia hispanica L.) selections. Industrial Crops and Products, 30(2), 321-324.

[10] 10.Álvarez-Chávez, L. M., Valdivia-López, M. D. L. A., AburtoJuarez, M. D. L., \& Tecante, A. (2008). Chemical characterization of the lipid fraction of Mexican chia seed (Salvia hispanica L.) International Journal of Food Properties, 11(3), 687-697. https://doi.org/10.1080/10942910701622656.

[11] Uzunova, G., Nikolova, K., Perifanova, M., Gentscheva, G., Marudova, M., \& Antova, G. (2016). Physicochemical characterisation of chia (Salvia hispanica) seed oil from Argentina. Bulg. Chem. Commun, 48, 131-135.
[12] Ayerza, R. (2009). The seed's protein and oil content, fatty acid composition, and growing cycle length of a single genotype of chia (Salvia hispanica L.) as affected by environmental factors. Journal of Oleo Science, 58(7), 347-354.

[13] AOAC, G. (2016). Official methods of analysis of AOAC International. Rockville, MD: AOAC International, ISBN: 978-0935584-87-5.

[14] Ichiahara, K. I., Shibahara, A., Yamamoto, K., \& Nakayama, T. (1996). An improved method for rapid analysis of the fatty acids of glycerolipids. Lipids, 31(5), 535-539.

[15] Christie, W. W. (2003). Determination of lipid profiles by gas chromatography. Lipids Analysis. $3^{\text {rd }}$ edition Christie WW, editor. Editor the Oily Press, Bridgwater (U.K.), 118-121.

[16] Ayerza, R. (2011). Seed yield components, oil content, and fatty acid composition of two cultivars of moringa (Moringa oleifera Lam.) growing in the Arid Chaco of Argentina. Industrial Crops and Products, 33(2), 389-394. https://doi.org/10.1016/j.indcrop.2010.11.003.

[17] Segura-Campos, M., Acosta-Chi, Z., Rosado-Rubio, G., ChelGuerrero, L., \& Betancur-Ancona, D. (2014). Whole and crushed nutlets of chia (Salvia hispanica) from Mexico as a source of functional gums. Food Science and Technology, 34(4), 701-709.

[18] Marineli, R., Moraes, É. A., Lenquiste, S. A., Godoy, A. T., Eberlin, M. N., \& Maróstica Jr, M. R. (2014). Chemical characterization and antioxidant potential of Chilean chia seeds and oil (Salvia hispanica L.). LWT-Food Science and Technology, 59(2), 1304-1310.

[19] Timilsena, Y. P., Vongsvivut, J., Adhikari, R., \& Adhikari, B. (2017). Physicochemical and thermal characteristics of Australian chia seed oil. Food Chemistry, 228, 394-402.

[20] CODEX, S. 210, 1999. Codex standard for named vegetable oils. Current official standards (Amended 2003, 2005). FAO/WHO Food standards. Codex Alimentarius.

[21] Barakat, H., \& Ghazal, G. A. (2016). Physicochemical Properties of Moringa oleifera Seeds and Their Edible Oil Cultivated at Different Regions in Egypt. Food and Nutrition Sciences, 7, 472-484. https://doi.org/10.4236/fns.2016.7604.

[22] Youssef, O., Guido, F., Mokhar, G., Nabil, B. Y., Daoud, D., \& Mokhtar, Z. (2011). The compositional quality and volatile compounds of samples from the blend of monovarietal olive oils cultivated in Tunisia. International journal of food science \& technology, 46(4), 678 686.

[23] Martinez, M.L, Marin, M., Faller S.M.C., Revol J., Penci, M.C. \& Ribotta, D. (2012). Chia salvia hispánica L Oil extraction: Study of processing parameters. Food Sciencce and Technology (47)78-82. 